\title{
Making Chauffeurs of Teamsters
}

\author{
By Harry S. Houpt
} $\mathrm{N}$ view of the rapidity with which motor trucks are
being adopted in all parts of the country it is interesting to consider whether it is more advisable to press a chauffeur into service as a motor truck driver or to use an ordinary teamster for the work.

The policy of a certain large motor truck company is to recommend the latter course, believing that the teamster better understands the matters of hauling and delivering goods, and is, therefore, closer to the details of handling traffic.

Of course, the teamster needs to be taught the operation of the motor truck. And for that reason the following method has been adopted.

When a company decides to abandon horses and install motor trucks it is recommended that the teamsters be sent to the motor truck factory. Here the first lessons are taught. For one week the drivers are placed in the care of an expert, and with him they go over the truck in the making. Various working parts of the truck are shown and an explanation is given as to the effect of neglect upon these parts. The proper care to be given is explained, and the physical operation of the truck also is gone into in detail.

The following week the drivers put the theories into actual practice. Instead of being put absolutely upon their own responsibility in the running of the truck, however, they are accompanied on trips by an instructor. The driver now gets his most valuable experience. For from three to five days, as the occasion may demand, he operates the truck, with the expert at his side to instruct him further on the fine points of driving. Handling the truck in crowded traffic until he gains the confidence required, the driver is now ready to take full charge of the vehicle. Apart from operating the truck, the new driver is also taught the duties in the way of caring for his machine. Th proper lubrication is emphasized; likewise, the things to do every morning before the truck is started on it day's work, and the mastering of simple adjustments now are known.

The good effect of a course of instruction such a this is easy to understand. The inexperienced teamster has in a brief time been made a finished motor truc driver. He has been made to feel the importance of the proper care of the vehicle. $\mathrm{He}$ is made not merely a motor truck enthusiast, but an expert. It is a fact that nine-tenths of the trouble experienced with moto trucks is due to ignorance on the part of the driver. This lack of knowledge makes itself known in neglect. The neglect is not wilful, and generally would not exist if the truck operator had been informed by practical methods how to run the truck, and the proper attention that it demands.

But the instruction does not end here. After the driver is pronounced capable of handling the truck, representative of the maintenance or service department keeps in close touch with him, and makes it point to care for the vehicle after it is sold. This representative calls upon the driver at stated intervals and inspects the working parts of the truck If the inspector finds that certain parts of the machinery are not properly oiled and cared for according to previous instructions, he points out the fact to the driver. In addition to these instructions, verbally given, books are furnished. These contain specific and minute instructions as to what the driver is expected to do from time to time to keep the truck in proper working order.

The advantages of making a motor truck driver out of a teamster are evident. The teamster is by nature better equipped to do his work. An automobile driver may know more about the mechanism of a truck, but he is unfamiliar with the type of work demanded of a motor truck driver. $\mathrm{He}$ is, therefore, unfitted for the duties of teaming.

In this course of instruction the inexperienced man is developed much after the method employed in instructing motor men on street cars. The ability he possesses as a truck teamster is brought out to its fullest possibilities, and the result is to make him much more enthusiastic and energetic about his work.

It is as logical for the teamster to become a motor truck operator as for the cab driver to be developed into a chauffeur. The problems of each are parallel. The teamster understands transportation of goods, and would be as unfitted to operate an automobile with ease as the cab driver is to drive a motor truck.

\section{Light and Heavy Car Costs Compared} POBABLY the majority of motorists who have en-
joyed automobiling during several successive years have started with the small runabout and passed through the light touring car class to the heavy touring car. The small car naturally stimulates the desire for the more powerful and more comfortable machine, with its superior speed, hill-climbing ability and endurance under heavy loads and over difficult roads. Except among the wealthy the transition from the small car to the larger one, and from the light car to the heavy one is accompanied by a serious consideration of the probable greater cost, both of the machine itseif and of the numerous items connected with its operation and maintenance. In a general way, it is known that it costs considerably more to keep and run a large car than a small one, but really definite knowledge or information of a comparative nature is rare and difficult to obtain.

The writer is happily able to give precise figures of the actual cost of motoring for a year each with two types of car, one a light touring car and the other a heavy machine of equal passenger seating capacity. The comparison of costs has the greater value because hoth cars were used by the samè owner, under practically identical conditions, and the records were kept by the owner himself in the same painstaking way. The tabulated comparison is given for ready reference, but it is necessary to make some explanatory statements so that no injustice will be done to either car.

Both cars were bought new and used in successive years, the light one weighing about 1,200 pounds and costing $\$ 1,150$, and the heavy one 3,000 pounds and listed at $\$ 2,200$. The former was in service for eleven months, averaging a little more than 800 miles per month, and the bigger machine was actually used ten months out of the full year, being out of service in September and February, but averaging 940 miles per month. Although rated as a five-passenger machine, the light car was really better suited for use by four adults, especially on long country runs. It was driven by a 20-horse-power engine, whereas the heavy car was rated at 35 horse-power.

It is rather surprising to find that the actual cost of leeping the larger car was very nearly twice as much as the expense of the light one; it is not safe to assume, however, that it was a bad investment; on the contrary, the owner is well pleased with it and satisfied with the change he made. After all, it is a question of how much one is able to pay for his enjoyment, the 100 per cent difference in expense being chargeable to factors that go to make up the continued relish of motoring. Every motorist knows what they are and why, if he can afford it, he is willing to pay double or triple or quadruple for his pleasure-each person's indulgence in his favorite pastime must be cut to the measure of his pocketbook. It is desirable, therefore, to know approximately what a certain amount of pleas-

\section{By Harry W. Perry}

ure, stated in terms of horse-power, speed, hill-climbing ability, roominess, comfort, reliability, appearance, etc will cost; hence the value of the accompanying statement.

A car that costs 100 per cent more than another wil of course double the item of interest on the investmen at 6 per cent, nearly double the premiums for insurance, and greatly increase the amount of depreciatio and in some States the amount to be paid for registration and driving licenses. One is scarcely prepared, however, to find that most of the running and upkee costs are also doubled, and especially that the tire expense is multiplied four times. With the light car the largest item of annual expense was the fuel, but with the large car it was the tires. The light car averaged more than fifty per cent more miles to the gallon of gasoline than the large machine, making 15.69 miles as compared with 10.93 miles per gallon. At the sam time, it occurred that the price of gasoline was raised several times during the periods covered, so that the average price during the second year was 17.3 as against 15.4 the year before. The prices of tires soare also, which accounts in some measure for the great difference in tire expenses during the two years. But the much heavier weight of the large car wore its tire out faster and the tires being of larger size necessarily cost more than those on the light car. Tires of 4 and $4 \frac{1}{2}$ inch sizes were fitted to the second year's machine, whereas the year previously the owner was able to use tires of 3 and $3 \frac{1}{2}$ inch sizes.

Of lubricating oil and grease the light car used 44 gallons in eleven months, so that average milage traveled per gallon was 213.6. As compared with this the heavier.car required 81.4 gallons during ten months' service and averaged 115.5 miles per gallon.

Under ordinary circumstances the storage on a large touring car would not be very much more than on a small one, but in the accompanying statement the item is almost double, which is accounted for by the fact that a new law went into effect between the first and second seasons that made it necessary for the owner to pay downtown storage during the day time when he drove to work in the large machine, whereas the summer before he had "stored" the small car in the street in front of his building during business hours.

In the matter of miscellaneous repairs the table shows a great discrepancy between the two machine which is unfair to the big car, because the total of $\$ 176.01$ includes a charge of $\$ 111.43$ for general overhauling and repainting at the end of the season to make it practically like new, whereas no such item is included in miscellaneous repairs on the small car, which was sold without repainting and overhauling. Yet it may be taken for granted that an allowance to cover this work figures in the item of depreciation, which was nearly 50 per cent on the small car, but is estimated at only about $331 / 3$ per cent on the large machine. Deducting the charge for overhauling places
mated at only about $331 / 3$ per cent on the large the expenses for miscellaneous repairs the second year at close to 50 per cent more than the first year. As a matter of fact, however, the owner really had much less mechanical trouble with the heavy car.

One other item needs explanation. It is that of insurance which cost disproportionately more the second year. This is because a policy to protect against collision was added to the insurance against fire and theft that was carried on the light car.

Oiling and greasing, which was done the first year by the owner, was done mostly by the dealer the second year, and is included in the miscellaneous repairs. Magneto ignition on the heavy car eliminated any charge for a spark coil which appears the first year, and a fine of $\$ 13$ paid the first year was avoided the following year. On the other hand, much more was paid out in small fees to drivers and helpers.

The reader may safely be allowed to draw his own conclusions from the facts presented, and decide whether the light or the heavy car is for him. Of course, it will be understood that the figures cannot he applied with any accuracy to cars of different types, uch as two-passenger runabouts and cross-country cars, or to machines of greatly different powers. Inasmuch as the two machines to which the actual expense items apply are average cars, the comparative figures should be of great value.

Comparative Cost of Light and Heavy Cars.

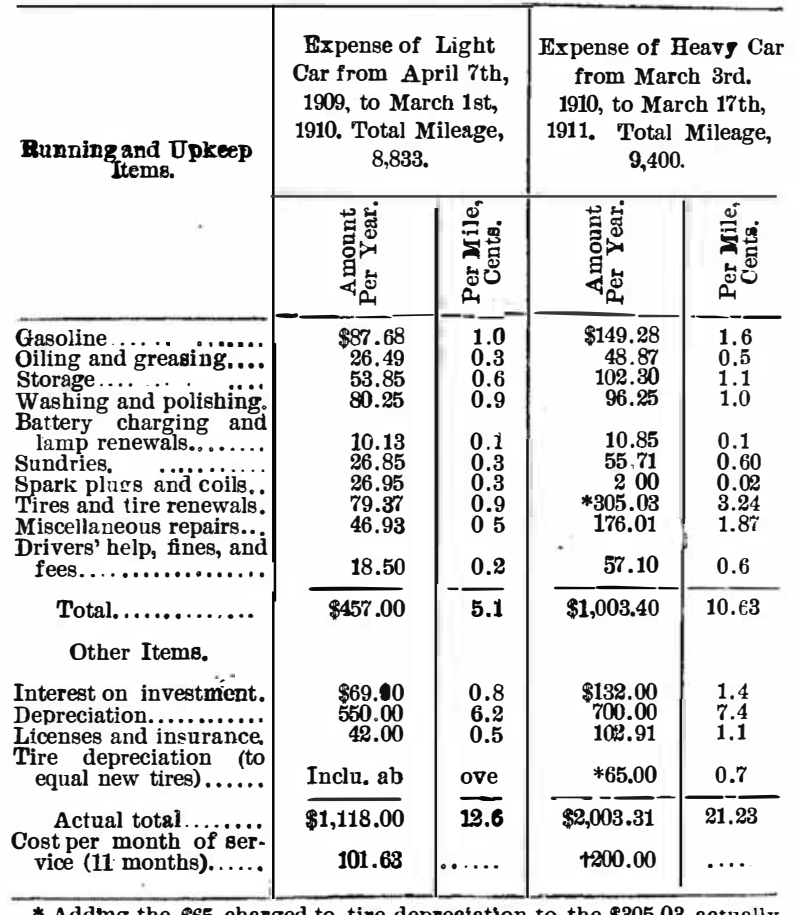

* Addmg the $\$ 65$ charged to tire depreciation to the $\$ 305.03$ actually paid for tire repairs and renewals makes the equivalent tire expense on the heavy car $\$ 370,03$, or approsimately 4 cents a mile. + Ten months. 